\title{
Strength Properties of Bio-composite Lumbers from Lignocelluloses of Oil Palm Fronds Agricultural Residues
}

\author{
Mohd Sukhairi Mat Rasat ${ }^{1}$, Razak Wahab ${ }^{2}$, Zulhisyam Abdul Kari ${ }^{3}$, Ag Ahmad Mohd Yunus ${ }^{4}$, Janshah \\ Moktar $^{5} \&$ Sitti Fatimah Mhd. Ramle
}

${ }^{1}$ Faculty of Earth Science, Universiti Malaysia Kelantan, Jeli Campus, 17600 Jeli, Kelantan E-mail:sukhairi@umk.edu.my

${ }^{2}$ Faculty of Earth Science, Universiti Malaysia Kelantan, Jeli Campus, 17600 Jeli, Kelantan E-mail: razak@umk.edu.my

${ }^{3}$ Faculty of Agro Based Industry, Universiti Malaysia Kelantan, Jeli Campus, 17600 Jeli, Kelantan E-mail: zulhisyam.a@umk.edu.my

${ }^{4}$ School of International Tropical Forestry, Universiti Malaysia Sabah, 88400 Kota Kinabalu, Sabah E-mail: agahmad@ums.edu.my

${ }^{5}$ School of International Tropical Forestry, Universiti Malaysia Sabah, 88400 Kota Kinabalu, Sabah E-mail:janshah@ums.edu.my

${ }^{6}$ Faculty of Earth Science, Universiti Malaysia Kelantan, Jeli Campus, 17600 Jeli, Kelantan E-mail: fatimah.n@umk.edu.my

\begin{abstract}
The physical and strength properties of bio-composite lumbers from agricultural residues of oil palm fronds were studied. Resins of phenol formaldehyde and urea formaldehyde were used as the binders. The oil palm fronds were obtained from an oil palm plantation in Kota Belud, Sabah. The fronds were segregated into three (3) groups of matured, intermediate and young of oil palm fronds. The leaflets and the epidermis were removed from the fronds before they were sliced longitudinally into thin layers. The layers were then compressed into uniform thickness of $2-3 \mathrm{~mm}$. The layers were air-dried and later mixed with resins using $12-15 \%$ of phenol and urea formaldehyde and recompressed with other layers forming the bio-composite lumbers. The bio-composite lumbers were then tested for their physical and strength properties. Testing was conducted in accordance to the International Organization for standardization (ISO) standard. The result on the physical and strength properties shows that the oil palm fronds bio-composite lumbers to be at par with solid rubberwood. Statistical analysis indicated significant differences between bio-composite lumbers made from each groups and portion, but no differences were observed in the type of resin used. The bio-composite lumbers from oil palm fronds agricultural residues has potential to be used as an alternative to wood to overcome the shortage in materials in the wood industry.
\end{abstract}

Keywords - Oil palm fronds, bio-composite lumbers, physical properties, strength properties.

\section{INTRODUCTION}

The increasing in timber prices and shortage of timber supply has affected the wood-based industries in the world [1]. The ever increasing manufacturing costs and uncertainty in wood supply in some region due to restrictions on logging and inadequate forest resources have caused increasing concerns over future wood supplies. The forest could not supply the woods in a huge amount anymore. To overcome this problem, research and development activities in many countries around the world including Malaysia has focus on bio-composites non-wood resources from agriculture residues as the alternative source for raw material. Nonwood lignocelluloses composites are becoming attractive in 
both commercial and non-commercial applications. Organic natural fibres are increasingly being investigated for various usages in many structural and non-structural applications. Malaysia produced big quantity of agricultural waste such as coir (Cocos nucifera) fibre, rice (Oryza sativa) husk and oil palm (Elaeis guinnesis) fibre [2]. Among the advantages of these fibres are renewable, non-abrasive, cheaper, abundance and show less health and safety concern during handling and processing. Many agro-residues are combined with other lignocelluloses material, metals, plastics, glass and synthetic fibres, and the properties of these composites are still studied [3].

Oil palm fronds which can be obtained all the year round can be answer on to overcome this problem because of its biomass appears to be the most viable alternative to be utilized as value added product as well as future wood-based industry [4]. Malaysia is currently the world's largest producer and exporter of palm oil. Malaysia produces about $47 \%$ of the world's supply for palm oil [5]. Malaysian palm oil industry generates huge quantity of oil palm biomass including oil palm trunk, oil palm frond, empty fruit bunch, shell and fibre in the production of palm oil.

Numerous research and development efforts undertaken to utilize empty fruit bunches contemplated mainly on the production of pulp for paper making [6]; [7] while a handful can also be found on the production of medium density fibreboard [8], oil palm fibre mattress and agricultural mats, high quality organic fertilizer, charcoal briquette and roof tiles [9]. The production of medium density fibreboard [10], particleboard [11], cement-bonded particleboard [12], fibre reinforced cement board [13]; [14], fibre plastic composite [15] and plywood [16]; [17] from oil palm trunk beside laminated veneer lumbers [18] and oil palm frond have shown to be technically feasible. Not many researches however are currently focusing on the potential uses of oil palm fronds as future alternative to woods. The oil palm fronds can be found in abundant all the year round.

The general objectives of these investigations were to investigate the properties of oil palm fronds bio-composite lumbers. These were achieved by assessing the physical and strength properties of oil palm fronds bio-composite lumbers from different of maturity and portion with phenol and urea formaldehyde resin.

\section{MATERIALS AND METHODS}

\section{A. Oil Palm Fronds Preparation}

The oil palm fronds were obtained from a private plantation in Kota Belud, in Sabah. The oil palm fronds were selected based on decay-free and no defect trees. The selected oil palm fronds were divided into three (3) groups of matured, intermediate and young oil palm fronds. Within these groups they were further sub-divided into bottom, middle and top portions. Leaflets were removed from the selected fronds. A part like disc about $10 \mathrm{~cm}$ in the middle were cut from every portion for the physical properties study for the raw oil palm frond and the rest were peeled of their skin and sliced in longitudinal direction. The fronds were then transport to Universiti Malaysia Sabah (UMS) for subsequent processing. The fronds were then sliced longitudinally of thickness 2-4 mm, and later compressed using rollers compressed machine to increase their density before undergoing air-drying.

\section{B. Air Drying}

All the compressed oil palm fronds then undergo an airdrying process for 12 hours until to remove in them. The air drying process was done to prevent the fungi and insects attacks. The drying process ends once the moisture content of these compressed fronds reached the equilibrium moisture content (14\% in Malaysia).

\section{Resin}

Two (2) types of resin were used in this study to produce the bio-composite lumbers. They were phenol formaldehyde (PF) and urea formaldehyde (UF) resin. Both types of resin were obtained from Sepanggar Chemical Sdn. Bhd.

\section{Oil Palm Fronds Bio-composite Lumbers Manufactured}

After undergoing dried in air-drying, the compressed oil palm fronds were then glued together with $12-15 \%$ of resins adding $1 \%$ of hardener $\left(\mathrm{NH}_{4} \mathrm{Cl}\right)$ forming layers manually using a forming box of $350 \times 350 \mathrm{~mm}$. After forming layers, the compressed oil palm fronds were pre-pressed by hand and then transferred to single-opening hydraulic hot-pressed machine with a platen temperature of $125 \pm 5^{\circ} \mathrm{C}$ for phenol formaldehyde resin, meanwhile $100 \pm 5^{\circ} \mathrm{C}$ for urea formaldehyde resin and pressed into desire shape for testing products making to form the oil palm fronds bio-composite lumbers. The oil palm fronds bio-composite lumbers were manufactured $20 \mathrm{~mm}$ in thickness from these three types of portion from three types of maturity groups using two different types of resin which are PF and UF.

The oil palm fronds bio-composite lumbers were pressed by means of a three-step-down method of pressing among 40 $\mathrm{sec} / \mathrm{mm}$ for phenol formaldehyde resin, meanwhile 30 $\mathrm{sec} / \mathrm{mm}$ for urea formaldehyde resin. Distances bars $20 \mathrm{~mm}$ in thickness were inserted between the hot platens during hot pressing. All this bio-composite lumbers were trimmed and cut into various size test specimens and then conditioned at $20 \pm 3^{\circ} \mathrm{C}$ and $65 \pm 3 \%$ relative humidity $(\mathrm{RH})$ for 72 hours prior for testing to produce an equilibrium moisture content of about $12 \pm 1 \%$.

\section{E. Physical Properties of Oil Palm Fronds Bio-composite Lumbers}

Physical properties were tested and evaluated in accordance with International Organization for Standardization (ISO) standards. Physical properties of oil palm fronds bio-composite lumbers were studied including density and basic density. 
1) Density: The density was determined by measuring the mass at $12 \%$ of moisture content and volume of each sample. Weight each test samples to an accuracy of $0.01 \mathrm{~g}$ by using analytical balance, meanwhile the volumes were determined by using water displacement method. The determination of density of each samples test was done in accordance ISO 3131-1975 [19]. The initial weight of specimens was taken and then oven-dried at $103 \pm 2^{\circ} \mathrm{C}$ until their moisture content reaches to $12 \%$. The oven-dried weight at $12 \%$ was determined and the specimens were slightly into the melting wax. By using water displacement method, initial level of volumetric cylinder was recorded and the weighting equipment was setup at two decimal places. The specimens were then immersed in the water. The weight and the latest water level of volumetric cylinder were recorded.

2) Basic Density: Basic density was determined by measuring the oven-dry weight and green volume of each sample. Weight each test samples to an accuracy of $0.01 \mathrm{~g}$ by using analytical balance, meanwhile the volumes were determined by using water displacement method. The determination of basic density of each test samples was done in accordance ISO 3131-1975 [19]. The initial weights of specimens were taken before undergoing to oven-dried at $103 \pm 2^{\circ} \mathrm{C}$ until their weights were constant. After the ovendried weight was determined, the specimens were dip slightly into the melting wax. By using water displacement method, initial level of volumetric cylinder was recorded and the weighing equipment was setup at two decimal places. The specimens were then immersed in the water. The weight and the latest water level of volumetric cylinder were recorded.

\section{F. Strength Properties of Oil Palm Fronds Bio-composite Lumbers}

Evaluation of strength properties was doing on oil palm fronds bio-composite lumbers. This evaluation was conducted according to International Organization for Standardization (ISO) standard (ISO 3349-1975 [20], ISO 3133-1975 [21] and ISO 3787-1976 [22]). Strength properties of oil palm fronds bio-composite lumbers were tested through the following method; static bending strength including modulus of elasticity (MOE) and modulus of rupture (MOR) besides compression strength for modulus of rupture (MOR).

1) Static Bending Strength: The static bending tests were conducted using A Universal Testing Machine. The dimensions of composite lumber sample for static bending test were according to ISO 3349-1975 [20] for MOE and ISO 3133-1975 [21] for MOR. The specimen was supported on a span of $280 \mathrm{~mm}$ and the force applied at the mid-span using a loading head. The tests were stopped when the samples started to break. The proportional limit with ultimate load and deflection were recorded, the MOE and MOR were calculated automatically by the computer connected to the machine.
2) Compression Strength: The compression strength test was performed according to ISO 3787-1976 [22] for MOR using a Universal Testing Machine. This test had been done with a constant rate of loading or constant rate of movement of the loading head of the machine till the test piece is broken.

\section{RESULTS AND DISCUSSIONS}

\section{A. Physical Properties of Oil Palm Fronds Bio-composite Lumbers}

Several physical properties of the oil palm fronds biocomposite lumbers were investigated in this study. They were density and basic density evaluation. In order to understand the oil palm fronds bio-composite lumbers behaviours and performances, it is necessary to consider first some of the basic physical properties which are affecting to its strength properties furthermore. All of the physical properties studied were investigated on the basic of its maturity groups, portions and resin types of the oil palm fronds bio-composite lumbers.

\section{1) Density of Oil Palm Fronds Bio-composite Lumbers:}

Density is an excellent indicator of the amount of substance contained in a piece of wood [23]. The density of the oil palm fronds bio-composite lumbers will depend on the maturity groups, portions and types of the resin that have been used for bonding this bio-composite lumbers. The density value that had been evaluated on the oil palm fronds bio-composite lumbers was determined at moisture content equal to $12 \%$.

Table 1 shows the results of mean value for density these bio-composite lumbers for each maturity group, portion and resin type. The highest density for these bio-composite lumbers was coming from the bottom portion for each maturity group followed by the middle and then top portions. Meanwhile, the matured maturity group possessed the highest density values for every portion compared to others follow by the intermediate and young maturity groups. It showed that all the density values decreased from the bottom to top portions for each maturity group, meanwhile the matured maturity group possessed the highest density values for every portion compared to others follow by the intermediate and young maturity groups.

The density values were affected by the anatomical structure in the oil palm fronds by its population of vascular bundles and parenchymatous tissues. This reinforced by the ANOVA in Table 6, there was a significant difference between density with maturity groups and portions, but there was no significant difference for the resins that had been used to produce the bio-composite lumbers. It means that, the types of resin were not influenced to the density value of the bio-composite lumbers.

However, the density of the oil palm fronds biocomposite lumbers more higher compared to the oil palm fronds density by the effect of resin penetration that have 
been used in producing this bio-composite lumbers. It was found that, the presence of both resins could increase the density of the oil palm fronds bio-composite lumbers that cause the increasing in material substance per unit volume in these bio-composite lumbers.

TABLE 1

MEAN VALUE FOR DENSITY OF OIL PALM FRONDS BIOCOMPOSITE LUMBERS

\begin{tabular}{lcccc}
\cline { 3 - 5 } Oil palm fronds & Resin used & Bottom & Middle & Top \\
\hline MATURED & PF & 0.45 & 0.44 & 0.42 \\
& UF & 0.46 & 0.43 & 0.42 \\
INTERMEDIATE & PF & 0.43 & 0.42 & 0.40 \\
& UF & 0.44 & 0.42 & 0.41 \\
YOUNG & PF & 0.42 & 0.41 & 0.40 \\
& UF & 0.42 & 0.41 & 0.40 \\
\hline
\end{tabular}

Note: Number of replicates for each parameter $=5$, Total number of replicates $=90, \mathrm{PF}=$ Phenol formaldehyde, UF $=$ Urea formaldehyde

2) Basic Density of Oil Palm Fronds Bio-composite Lumbers: The measuring basic density value for oil palm fronds bio-composite lumbers were similar to density value evaluation where the different between calculating density value and basic density value based on weight at moisture content equal to $12 \%$ percent for density value, meanwhile pure oven-dry weight for basic density value which were according to Organization for Standardization (ISO) standard (ISO 3131-1975) [19].

The mean values of basic density for the oil palm fronds bio-composite lumbers for each maturity group, portion and resin type were shown in Table 2 . The results showed that all the basic density values decreased from the bottom to top portions for each maturity group, meanwhile the matured maturity groups possessed the highest basic density values for every portion compared to others follow by the intermediate and young maturity groups. Their trend was similar to the density value, just different in number value because of its way calculation has been done.

According to the obtained results in Table 2, the decreased summarized oil palm fronds bio-composite lumbers basic density from the bottom to top portions for each maturity group and from the matured to young maturity groups for each portion were same situation with the basic density value of the oil palm fronds. The high concentration of fibrous vascular bundles, especially at the bottom portion of the oil palm fronds possessed higher in basic density value compared to other portions [24].

Rowell [25] stated that basic density values for wood were differently according to their cell size, cell wall thickness and relative amount of solid cell wall material. He mentioned that more mature and thickly cells were have been on bottom part of wood, thus cause the higher basic density values than others part. This statement agreement with basic density values that had been recorded in this study where the oil palm fronds bio-composite lumbers from the bottom portion got higher in basic density value than other portions. This is supported by Haygreen and Bowyer [26], where they reported that the basic density values were decreased from bottom part of a wood to top part because of their differences growing that cause the anatomical cell maturity development. The same authors also mentioned that the densities as well as basic density are the main physical properties that will affected the strength properties of wood. They noted that at the same moisture content of wood, the higher value in densities as well as basic density possessed the higher in strength properties and this will be discussed on the next subtopic.

ANOVA in Table 6 showed that there was a significant difference between basic density with maturity groups and portions, but there was no significant difference for the resin types that had been used to produce the bio-composite lumbers. It means that, the types of resin were not influenced to the basic density value of the bio-composite lumbers. However, the basic density of oil palm fronds bio-composite lumbers more higher compared to the oil palm fronds basic density by the effect of resin that have been used in producing this bio-composite lumbers. The increasing of oil palm fronds bio-composite lumbers basic density probably related to resin penetration into the bio-composite lumbers. Previous study by Paridah and Anis [27] report that parenchyma behaves like a sponge and can easily absorb moisture. Therefore, the bio-composite lumbers could easily absorb phenol and urea formaldehyde resin during producing process and leads to increase in the basic density of the oil palm fronds bio-composite lumbers. It is assumed that the resin penetrations possessed higher density as well as basic density and enhance the strength of the bio-composite lumbers.

TABLE 2

MEAN VALUE FOR BASIC DENSITY OF OIL PALM FRONDS BIOCOMPOSITE LUMBERS

\begin{tabular}{lcccc} 
& & \multicolumn{3}{c}{ Basic density of portions $\mathbf{( g / \mathbf { c m } ^ { \mathbf { 3 } } )}$} \\
\hline Oil palm fronds & $\begin{array}{c}\text { Resin } \\
\text { used }\end{array}$ & Bottom & Middle & Top \\
\hline MATURED & PF & 0.38 & 0.36 & 0.33 \\
& UF & 0.39 & 0.35 & 0.32 \\
INTERMEDIATE & PF & 0.36 & 0.35 & 0.32 \\
& UF & 0.37 & 0.34 & 0.31 \\
YOUNG & PF & 0.34 & 0.33 & 0.30 \\
& UF & 0.34 & 0.32 & 0.30 \\
\hline
\end{tabular}

Note: Number of replicates for each parameter $=5$, Total number of replicates $=90, \quad \mathrm{PF}=$ Phenol formaldehyde, $\mathrm{UF}=$ Urea formaldehyde

\section{B. Strength Properties of Oil Palm Fronds Bio-composite Lumbers}

The strength properties of wood are measures of its resistance to exterior forces which tend to deform its mass [28]. The resistances of wood to such forces depend on their magnitude and the manner of loading (bending, compression, shear, tension, etc.). Due to the strength 
properties, Tsoumis [29] stated that wood exhibits different strength properties in different growth directions, therefore it is mechanically anisotropic. According to Bowyer et al. [30], strength properties are usually the most important characteristics of wood product to be used in structural applications. A structural application is any use for which strength is one of the primary criteria for selection of the material. Structural uses of wood product include floor joint and rafters, wall sheathing and sub flooring [28].

Regarding the strength properties of the oil palm fronds bio-composite lumbers, several strength properties were tested in this study, including static bending strength (MOE and MOR) and compression strength (MOR). The testing was carried out on the basis of International Organization for Standardization (ISO) standard for the strength properties evaluation. The analysis of strength properties of the oil palm fronds bio-composite lumbers were particularly investigated the effect of maturity groups, portions and types of resin. The resins that have been used in producing the biocomposite lumbers were phenol and urea formaldehyde.

In addition, due to the original unit of force during the testing material, all the force-unit for strength testing is in Newton-force, for example unit for modulus of elasticity in $\mathrm{N} / \mathrm{mm}^{2}$, but in order to have the value in $\mathrm{kg} / \mathrm{cm}^{2}$, the force value can be converted into International System of Unit [31].

1) Static Bending Strength of Oil Palm Fronds Biocomposite Lumbers: The static bending strength refers to tests performed in which a bending stress is applied to the specimen to determine the stiffness or MOE of the specimen as well as the amount of force required to cause the specimen to fail, expressed as the MOR [28]. Bending strength of wood is usually expressed in term of the MOR [28]. These properties are the most important parameters which usually are used for engineering purposes.

In order to investigate the static bending of the oil palm fronds bio-composite lumbers, the analysis data was conducted to examine the effect of maturity groups (matured, intermediate and young), portions (bottom, middle and top) and resins (phenol and urea formaldehyde) to the MOE and MOR. The summarized mean result of static bending test including MOE and MOR strength is presented in Table 3 and 4. It showed that the bottom portion got the highest value for both MOE and MOR strength in static bending for every maturity group, meanwhile the matured maturity group possessed the highest value for each portion compared to the intermediate and young maturity groups.

It is clearly observed that the values of the oil palm fronds bio-composite lumbers both from phenol and urea formaldehyde resin for MOE and MOR in static bending were decrease from the bottom to top portions for every maturity group and from the matured to young maturity groups for each portion respectively.
According to the obtained results of static bending test which is summarized in Table 3 for modulus of elasticity (MOE) strength, it showed that the average values of the matured maturity group from the bottom, middle and top portions for phenol formaldehyde bio-composite lumbers were $999.61,952.29$ and $844.18 \mathrm{~N} / \mathrm{mm}^{2}$. Meanwhile, the average values MOE for urea formaldehyde bio-composite lumbers were $980.31,949.40$ and $840.40 \mathrm{~N} / \mathrm{mm}^{2}$ respectively from the bottom, middle and top portions for matured maturity group. It was observed that the MOE strength were decrease from the bottom to top portion for matured maturity group both of phenol either urea formaldehyde biocomposite lumbers and the same situation were done for others two maturity groups which were the intermediate and young maturity groups.

TABLE 3

MODULUS OF ELASTICITY (MOE) STATIC BENDING STRENGTH OF OIL PALM FRONDS BIO-COMPOSITE LUMBERS

Static bending MOE of portions $\left(\mathrm{N} / \mathrm{mm}^{2}\right)$

\begin{tabular}{lcccc}
\hline Oil palm fronds & $\begin{array}{c}\text { Resin } \\
\text { used }\end{array}$ & Bottom & Middle & Top \\
\hline MATURED & PF & 999.61 & 952.29 & 844.18 \\
& UF & 980.31 & 949.40 & 840.40 \\
INTERMEDIATE & PF & 979.15 & 942.44 & 817.29 \\
& UF & 953.93 & 928.34 & 776.04 \\
YOUNG & PF & 935.36 & 837.24 & 761.14 \\
& UF & 936.24 & 836.67 & 666.30 \\
\hline
\end{tabular}

Note: Number of replicates for each parameter $=5$, Total number of replicates $=90, \quad \mathrm{PF}=$ Phenol formaldehyde, $\mathrm{UF}=$ Urea formaldehyde

Looking at the average values of MOE for maturity groups, the values for the bottom portion were having been discussing as a comparison. According to the result, the average value of MOE strength for the bottom portion from the matured, intermediate and young maturity groups of phenol formaldehyde bio-composite lumbers were 999.61, 979.15 and $935.36 \mathrm{~N} / \mathrm{mm}^{2}$ respectively. Further, the mean value of MOE strength for the bottom portion of urea formaldehyde bio-composite lumbers were 980.31, 953.93 and $936.24 \mathrm{~N} / \mathrm{mm}^{2}$ from the matured, intermediate and young maturity groups. Based on this distribution result, it showed that the average value of MOE strength was a decrease from the matured to young maturity groups for the bottom portion either for phenol or urea formaldehyde biocomposite lumbers and there were happened to the middle and top portions too according from the matured, intermediate and young maturity groups.

Beside the MOE, the wood strength when the specimen reached the breaking point and then it was not able to recovery its shape, where the load achieves its maximum value, it's called MOR. This strength property is one of the important parameter which usually used for engineering purposes. Relating to the result test of MOR of the oil palm fronds bio-composite lumbers at the different maturity groups, portions and resin types, the summarized data of mean values is presented in Table 4 . 
TABLE 4

MODULUS OF RUPTURE (MOR) STATIC BENDING STRENGTH OF OIL PALM FRONDS BIO-COMPOSITE LUMBERS

\begin{tabular}{lcccc}
\cline { 3 - 5 } & & \multicolumn{3}{c}{$\begin{array}{c}\text { Static bending MOR of } \\
\text { portions (N/mm }\end{array}$} \\
\hline Oil palm fronds & $\begin{array}{c}\text { Resin } \\
\text { used }\end{array}$ & Bottom & Middle & Top \\
& PF & 16.66 & 12.55 & 11.72 \\
MATURED & UF & 15.40 & 12.38 & 11.63 \\
INTERMEDIATE & PF & 14.38 & 12.37 & 10.87 \\
& UF & 12.62 & 12.07 & 10.51 \\
YOUNG & PF & 12.16 & 11.62 & 10.27 \\
& UF & 12.25 & 11.19 & 9.10 \\
\hline
\end{tabular}

Note: Number of replicates for each parameter $=5$, Total number of replicates $=90, \mathrm{PF}=$ Phenol formaldehyde, $\mathrm{UF}=$ Urea formaldehyde

Based on the result in Table 4, the MOR of the oil palm fronds bio-composite lumbers was gradually decreasing from the bottom to top portions for each maturity group and from matured to young maturity groups for every portion. This including for both two types of the resin that have been used in producing the bio-composite lumbers which were phenol and urea formaldehyde resin. The MOR strength for the matured maturity group from the bottom, middle and top portions were $16.66,12.55$ and $11.72 \mathrm{~N} / \mathrm{mm}^{2}$ respectively for the oil palm frond bio-composite lumbers used phenol formaldehyde resin, while the MOR values for urea formaldehyde bio-composite lumbers were 15.40, 12.38 and $11.63 \mathrm{~N} / \mathrm{mm}^{2}$ respectively. This trend was also similar to the intermediate and young maturity groups according from the bottom towards top portions.

Further, in order to investigate the effect of maturity groups of oil palm fronds in producing this bio-composite lumbers to MOR in static bending strength, the data was carried out to examine the distribution of MOR values like shown in Table 4 based on mean value. From the obtained result, it showed that for the bottom portion for each maturity group which was the matured, intermediate and young maturity groups from phenol formaldehyde biocomposite lumbers, the values was $16.66,14.38$ and 12.16 $\mathrm{N} / \mathrm{mm}^{2}$, meanwhile the MOR value for urea formaldehyde bio-composite lumbers was $15.40,12.62$ and $12.25 \mathrm{~N} / \mathrm{mm}^{2}$ respectively. This strength values respectively decreased from the matured towards maturity groups for bottom portion either both of resin types that have been used in this bio-composite lumbers. The MOR value were decreasing too to others two portions which was the middle and top portions towards maturity groups from matured, intermediate and young maturity groups. This trend was also similar to MOE value effect by portions where the MOR values were decreasing from bottom to top portions for each maturity group as well as from old towards young maturity groups for every portion.

It is clearly observed that the values of both MOE and MOR for the oil palm fronds bio-composite lumbers were decrease towards the portions from bottom, middle and top portions as well as towards the maturity groups from matured, intermediate and young maturity groups. These were happen to both of the bio-composite lumbers made from phenol and urea formaldehyde resin.

According to Rulliarty and America [32], the trend of variations in MOE and MOR values along the tree height can be explained by the decrease in maturity of wood and fibre length from bottom to top of the tree. This statement was logically accepted due to the presence of vascular bundles decrease from the bottom to top portions along the oil palm fronds as well as from the matured to young maturity groups. It is because the presence of vascular bundle will affect the quantity of fibre cell that cause the density and basic density values in higher results. According to Haygreen and Bowyer [26], the higher result in density and basic density values are the main physical properties that will affected the strength properties of wood. Based on Haygreen and Bowyer statement, it can be indentified why the bottom portion got higher value both for MOE and MOR strength compare than the middle and top portions for each maturity group as well as matured maturity group than intermediate and young maturity groups for every portion.

The strength properties of wood have a close and significant correlation with density and basic density [33]. The MOE and MOR strength of the oil palm fronds biocomposite lumbers from the bottom portion produced higher result than middle and top portions for each maturity group as well as towards matured, intermediate and young maturity groups for every portion. This reinforced by the ANOVA in Table 6, there was a significant difference between MOE and MOR of static bending with maturity groups and portions.

The obtained result showed that the bio-composite lumbers from phenol formaldehyde resin possessed the higher value both of MOE and MOR test than urea formaldehyde resin. Due to the factor of urea formaldehyde resin, it has high amount of solid content compared to phenol formaldehyde resin. Therefore, the distribution of phenol formaldehyde resin was located irregularly in the biocomposite lumbers structures [23]. In addition, when the stress was applied, the stress could not be transferred consistently between the fibre and matrix. Besides this, the penetration of high viscosity of urea formaldehyde resin probably breaks the cell wall of the oil palm fronds biocomposite lumbers [23]. This action would make the fibre and matrix impossible to withstand greater loads. However, according to ANOVA in Table 6, the result of MOE and MOR of static bending did not show significantly difference with resin types. It means that, the types of resin were not too much influenced to the density value of the biocomposite lumbers.

2) Compression Strength of Oil Palm Fronds Biocomposite Lumbers: In this subtopic, the study was conducted to investigate the compression strength of oil palm fronds bio-composite lumbers. The experiment runs in using the Universal Testing Machine. Compression strength is defined as the maximum stress sustained by compression of a specimen with the specimen having a ratio of length to 
smallest dimension [34]. While, Ronald and Gjinoli [35] reported that the characteristic of the compression load deformation curve were similar to those for static bending strength. The compression strength of composite is strongly dependent on the effectiveness of the matrix in supporting the fibre against buckling [36].

Testing on this strength property was conducted in accordance to the ISO 3787-1976 [22]. The obtained data was examined using statistical analysis to define the effect of three parameters like static bending strength test, which were based on maturity groups (matured, intermediate and young), portions (bottom, middle and top) including types of resin (phenol and urea formaldehyde) to the compression strength of the oil palm fronds bio-composite lumbers.

Table 5 showed the compression strength value of matured maturity group from bottom to top portions were $473.17,395.93$ and $260.22 \mathrm{~N} / \mathrm{mm}^{2}$ for phenol formaldehyde bio-composite lumbers, while for the urea formaldehyde biocomposite lumbers, the result were 459.52, 344.60 and $260.00 \mathrm{~N} / \mathrm{mm}^{2}$ respectively. It can be observed that the compression strength were decrease from bottom portion towards to middle and top portions for matured maturity group. The similar decrement distribution data have been done too for intermediate and young maturity groups towards from bottom, middle and top portions.

In order to investigate the effect of maturity groups to compression strength of oil palm fronds bio-composite lumbers, the data in Table 5 showed that the trend for each portion towards matured, intermediate and young maturity groups were similar to portion factor from bottom to top portions. The result of bottom portion according from matured, intermediate and young maturity groups were 473.17, 453.67 and $301.49 \mathrm{~N} / \mathrm{mm}^{2}$ for phenol formaldehyde bio-composite lumbers, meanwhile the obtained result 459.52, 431.88 and $312.94 \mathrm{~N} / \mathrm{mm}^{2}$ respectively for urea formaldehyde bio-composite lumbers. It is clearly showing the decrement towards matured, intermediate and young maturity groups for the bottom portion and this was happen to others two portions which were middle and top portions.

TABLE 5

MODULUS OF RUPTURE (MOR) COMPRESSION STRENGTH OF OIL PALM FRONDS BIO-COMPOSITE LUMBERS

\begin{tabular}{lcccc}
\cline { 3 - 5 } & & \multicolumn{3}{c}{$\begin{array}{c}\text { Compression MOR of } \\
\text { portions }\left(\mathbf{N} / \mathbf{m m}^{2}\right)\end{array}$} \\
\hline Oil palm fronds & $\begin{array}{c}\text { Resin } \\
\text { used }\end{array}$ & Bottom & Middle & Top \\
& PF & 473.17 & 395.93 & 260.22 \\
MATURED & UF & 459.52 & 344.60 & 260.00 \\
INTERMEDIATE & PF & 453.67 & 318.88 & 196.71 \\
& UF & 431.88 & 274.90 & 190.70 \\
YOUNG & PF & 301.46 & 235.60 & 183.48 \\
& UF & 312.94 & 198.79 & 181.06 \\
\hline
\end{tabular}

Note: Number of replicates for each parameter $=5$, Total number of replicates $=90, \mathrm{PF}=$ Phenol formaldehyde, $\mathrm{UF}=$ Urea formaldehyde
The decrement trend of MOR in compression strength that has been shown absolutely similar to the trend of MOE and MOR in static bending strength. This is caused by the differences vascular bundles population along the oil palm fronds, thus affected the value of density as well as basic density. The differences of density and basic density value encourage the distribution result of compression strength for the maturity groups and portions, where the bottom portion got higher result in compression strength than middle and top portions for each maturity group as well as for matured maturity group follow by intermediate and young maturity groups for every portion. This reinforced by ANOVA in Table 6 that showed there was a significant difference between compression strength with maturity groups and portions.

According to Oyagade and Fasulu [37], they reported that generally for each of the species, wood density and strength properties decrease with increment in tree height and this can be apply along the oil palm fronds toward bottom, middle and top portions plus from old to young maturity groups. Some strength properties of wood according to Nordahlia [38] noted that compression failure typically occurs in low density of wood.

The obtained result showed that the average value for each part of phenol formaldehyde bio-composite lumbers possessed higher result in compression strength than urea formaldehyde bio-composite lumbers. Higher compression strength of oil palm fronds bio-composite lumbers with phenol formaldehyde resin as compared to urea formaldehyde bio-composite lumbers can be due to the fact that phenol formaldehyde resin, when properly cured, is often tougher that the wood itself as stated by Baldwin [4].

The effectiveness of phenol and urea formaldehyde resin in enhancing compression properties showed a similar trend as static bending strength, where the phenol formaldehyde bio-composite lumbers possessed more higher value of compression strength compared to urea formaldehyde biocomposite lumbers, but the differences result was not observed a significant difference based on ANOVA in Table 6 between compression strength with the types of resin. Thus, it showed that the effect types of resin not encourage too much of compression strength of this bio-composite lumbers.

\section{Analysis of Variance (ANOVA) on Physical and Strength Properties of Oil Palm Fronds Bio-composite Lumbers}

Table 6 shows the ANOVA for physical and strength properties of the oil palm fronds bio-composite lumbers. The analysis was conducted to determine whether there was exist or not the significance difference between physical properties (density and basic density) and strength properties (MOE for static bending strength and MOR for static bending including compression strength) with maturity groups, portions and types of resin of the oil palm fronds bio-composite lumbers. 
TABLE 6

ANOVA ON PHYSICAL AND STRENGTH PROPERTIES OF OIL PALM FRONDS BIO-COMPOSITE LUMBERS

\begin{tabular}{|c|c|c|c|c|c|}
\hline Source of Variance & Dependent Variable & Sum of Square & Df & Mean Square & F-Ratio \\
\hline \multirow{5}{*}{ Maturity } & $\mathrm{D}$ & 0.0108 & 2 & 0.0054 & $7.94 * *$ \\
\hline & $\mathrm{BD}$ & 0.0180 & 2 & 0.0197 & $28.75^{* *}$ \\
\hline & $\mathrm{MOEb}$ & 155675.0000 & 2 & 77837.5000 & $57.05 * *$ \\
\hline & MORb & 79.0218 & 2 & 39.5109 & $40.39 * *$ \\
\hline & MORc & 255794.0000 & 2 & 127897.0000 & $63.81 * *$ \\
\hline \multirow{5}{*}{ Portion } & $\mathrm{D}$ & 0.0112 & 2 & 0.0056 & $8.26 * *$ \\
\hline & $\mathrm{BD}$ & 0.0394 & 2 & 0.0090 & $28.75 * *$ \\
\hline & $\mathrm{MOEb}$ & 507856.0000 & 2 & 253928.0000 & $186.12 * *$ \\
\hline & MORb & 157.7170 & 2 & 78.8586 & $80.62 * *$ \\
\hline & MORc & 565023.0000 & 2 & 282512.0000 & $140.95 * *$ \\
\hline \multirow{5}{*}{ Resin } & $\mathrm{D}$ & 0.0001 & 1 & 0.0001 & $0.20 \mathrm{~ns}$ \\
\hline & $\mathrm{BD}$ & 0.0004 & 1 & 0.0004 & $1.28 \mathrm{~ns}$ \\
\hline & $\mathrm{MOEb}$ & 11232.8000 & 1 & 11232.8000 & $8.23 \mathrm{~ns}$ \\
\hline & MORb & 8.2313 & 1 & 8.2313 & $8.41 \mathrm{~ns}$ \\
\hline & MORc & 7538.0100 & 1 & 7538.0100 & $3.76 \mathrm{~ns}$ \\
\hline
\end{tabular}

Note: $* *=$ significant at $\mathrm{p} \leq 0.01, \mathrm{~ns}=$ not significant, $\mathrm{D}=$ Density, $\mathrm{BD}=$ Basic density, $\mathrm{MOEb}=$ Modulus of elasticity for static bending strength, $\mathrm{MORb}=$ Modulus of rupture for static bending strength, MORc $=$ Modulus of rupture for compression strength, Total number of samples for each testing $=90$

Based on the ANOVA in Table 6, there were significant differences between physical properties (density and basic density) and strength properties (static bending strength (MOE and MOR) and compression strength (MOR)) with the maturity groups and portions factors. It possessed that the significant differences between them were at P-value $\leq$ 0.01. The obtained result shows that for all physical and strength properties that have been investigate towards oil palm fronds bio-composite lumbers in this study show the significant differences with the maturity groups as well as the portions. It means that maturity groups and portions were affected and influenced for the result of physical and strength properties values of the bio-composite lumbers.

Meanwhile, there was no significant difference exist between physical properties (density and basic density) and strength properties (static bending strength (MOE and MOR) and compression strength (MOR)) with the types of resin factors. According to the ANOVA in Table 6, there was no encouragement of resin types to the physical and strength properties of the oil palm fronds bio-composite lumbers, although there was differences in value for the testing result for each part which were the testing result from phenol formaldehyde bio-composite lumbers possessed more higher value than urea formaldehyde bio-composite lumbers and has been discussed before this. It means whether using phenol or urea formaldehyde resin in producing the biocomposite lumbers will give quite similar in values testing result.

\section{Correlation Coefficient between Physical and Strength Properties of Oil Palm Fronds Bio-composite Lumbers}

The correlation among physical and strength properties of the oil palm fronds bio-composite lumbers is presented in Table 7. There was a correlation between physical properties (density and basic density) of oil palm fronds bio-composite lumbers with maturity groups and portions. Negative correlations were observed between density and maturity groups $(r=-0.3657)$ and portions $(r=-0.3748)$. Meanwhile, basic density value for this bio-composite lumbers ( $\mathrm{r}=$ $0.4435, r=-0.6588$ ) were negatively correlated with maturity groups and portions.

From matured to young maturity groups for each portion and towards bottom, middle and top portions for every maturity group, there were decreasing in density as well as basic density values. These were supported by negative correlation between them as been shown in Table 7 and have significant differences in ANOVA displayed in Table 6. There was also possessed a correlation coefficient between density with basic density $(r=0.5611)$ in this study. A positive correlation was observed between of them and there was a significant difference at $\mathrm{P}$-value $\leq 0.01$. Besides that, a positive correlation relationship exist between resin types with density value $(r=0.0411)$, while negative correlation was possessed among resin types and basic density value ( $\mathrm{r}$ $=-0.0668$ ). However, these correlation relationship were not significant between them like stated in ANOVA in Table 6, thus mean that types of resin factor was not affected the density as well as basic density value of the oil palm fronds bio-composite lumbers because of its correlation coefficient value too small.

The correlation between the strength properties (MOE for static bending strength and MOR for static bending including compression strength) with others oil palm fronds bio-composite lumbers properties are presented in Table 7. There was a correlation between maturity groups factor with the strength properties values. Negative correlation were obtained between maturity groups with MOE of static bending strength $(\mathrm{r}=-0.4321)$, MOR of static bending strength $(r=-0.4927)$ and MOR for compression strength $(r$ $=-0.5029)$. While, similar trend correlation were obtained too between portions with MOE of static bending strength ( $\mathrm{r}$ $=-0.7862)$, MOR of static bending strength $(r=-0.6939)$ and last but not least MOR for compression strength $(\mathrm{r}=$ 0.7481). 
TABLE 7

CORRELATION ANALYSIS BETWEEN PHYSICAL AND STRENGTH PROPERTIES OF OIL PALM FRONDS BIO-COMPOSITE LUMBERS

\begin{tabular}{|c|c|c|c|c|c|c|c|c|}
\hline & Maturity & Portion & Resin & $\mathrm{D}$ & $\mathrm{BD}$ & $\mathrm{MOEb}$ & MORb & MORc \\
\hline Maturity & 1 & $0.0000 \mathrm{~ns}$ & $0.0000 \mathrm{~ns}$ & $-0.3657 * *$ & $-0.4435 * *$ & $-0.4321 * *$ & $-0.4927 * *$ & $-0.5029 * *$ \\
\hline Portion & & 1 & $0.0000 \mathrm{~ns}$ & $-0.3748 * *$ & $-0.6588 * *$ & $-0.7862 * *$ & $-0.6939 * *$ & $-0.7481 * *$ \\
\hline Resin & & & 1 & $0.0411 \mathrm{~ns}$ & $-0.0668 \mathrm{~ns}$ & $-0.1196 n s$ & $-0.1592 \mathrm{~ns}$ & $-0.0867 \mathrm{~ns}$ \\
\hline D & & & & 1 & $0.5611 * *$ & $0.3750 * *$ & $0.4045^{* *}$ & $0.5339 * *$ \\
\hline $\mathrm{BD}$ & & & & & 1 & $0.7241 * *$ & $0.6669 * *$ & $0.7356 * *$ \\
\hline MOEb & & & & & & 1 & $0.7673 * *$ & $0.7870^{* *}$ \\
\hline MORb & & & & & & & 1 & $0.7889 * *$ \\
\hline MORc & & & & & & & & 1 \\
\hline
\end{tabular}

Note: $* *=$ significant at $\mathrm{p} \leq 0.01, \mathrm{~ns}=$ not significant, $\mathrm{D}=$ Density, $\mathrm{BD}=$ Basic density, $\mathrm{MOEb}=$ Modulus of elasticity for static bending strength, $\mathrm{MORb}=$ Modulus of rupture for static bending strength, MORc $=$ Modulus of rupture for compression strength, Total number of samples for each testing $=90$

The negative correlation between maturity groups and portions with strength properties (MOE and MOR for static bending strength and MOR for compression strength) means that the strength of oil palm fronds bio-composite lumbers decreases towards bottom, middle and top portions for each maturity group as well as from matured to young maturity groups for every portion. The ANOVA presented in Table 6 shows significant difference at $\mathrm{P}$-value $\leq 0.01$.

The strength properties of wood have a close and significant correlation with density as well as basic density [33]. Increment of density and basic density value increases the strength properties of wood including static bending and compression strength. This statement is supported in the correlation analysis shown in Table 7 . The positive correlation coefficient occurred between density and basic density value with strength properties (MOE and MOR of static bending strength and MOR of compression strength) of oil palm fronds bio-composite lumbers towards maturity groups (matured to young maturity groups) and portions (bottom to top portions). Positive correlation were obtained between density with MOE of static bending strength $(\mathrm{r}=$ $0.3750)$, MOR of static bending strength $(r=0.4045)$ and MOR of compression strength $(r=0.5339)$, while correlation between basic density with these three strength testing that has been done in this study were $r=0.7241$ and $r=0.6669$ for MOE and MOR of static bending strength and $r=0.7356$ for MOR of compression strength. All of these correlations possessed significant differences at $\mathrm{P}$-value $\leq 0.01$ according to the ANOVA in Table 6.

The effect of resin types on the strength properties of oil palm fronds bio-composite lumbers, there posses negative correlation among of them, where $r=-0.1196$ and $r=-$ 0.1592 for MOE and MOR of static bending strength, while $r=-0.0867$ for MOR of compression strength. It was similar trend to correlation relationship between physical properties (density and basic density) of oil palm fronds bio-composite lumbers with types of resin. Although, they possessed a correlation relationship, but there were not significant between of them according to ANOVA in Table 6. It means that the types of resin not affected too much to strength properties of this bio-composite lumbers similar to physical properties. Positive correlation were observed among of these three strength properties, where $r=0.7673$ and $r=0.7870$ between MOE of static bending strength with MOR of static bending and compression strength, while $r=$ 0.7889 between MOR of static bending strength with MOR of compression strength and these correlation coefficient were possessed significant differences at $\mathrm{P}$-value $\leq 0.01$.

\section{IV.CONCLUSIONS}

\section{A. Physical Properties}

The bio-composite lumbers made from matured oil palm fronds possess the highest values in density and basic density. This is followed by the intermediate and young fronds. The same trends were observed in the bottom, middle and top portions of the oil palm fronds. For the maturity groups factor, there was the decrement resulting in basic density value of oil palm fronds bio-composite lumbers through matured, intermediate and young maturity groups for every portion that have been used in producing this biocomposite lumbers. The basic density value for the bottom, middle and top portion from the matured maturity group that have converted to bio-composite lumbers using phenol formaldehyde were $0.38,0.36$ and $0.33 \mathrm{~g} / \mathrm{cm}^{3}$ respectively. The basic density of $0.38,0.36$ and $0.34 \mathrm{~g} / \mathrm{cm}^{3}$ were obtained from the phenol formaldehyde bio-composite lumbers of the bottom portion of matured, intermediate and young maturity groups showed the decrement of basic density value through the maturity groups for each portion.

\section{B. Strength Properties}

The MOE for static bending strength for the oil palm fronds bio-composite lumbers can reach to maximum value of $999.61 \mathrm{~N} / \mathrm{mm}^{2}$ made from the bottom portion of matured maturity group using phenol formaldehyde, while the lowest value was coming from urea formaldehyde bio-composite lumbers from the top portion of young maturity group which was $666.30 \mathrm{~N} / \mathrm{mm}^{2}$. There was a decrement of MOE in static bending strength of oil palm fronds bio-composite lumbers from the bottom, middle and top portions for each maturity group. The same trends also happened to the oil palm fronds bio-composite lumbers made from the matured, intermediate and young maturity groups for every portion. The result from phenol formaldehyde bio-composite lumbers of 
matured maturity group from the bottom, middle and top portion were 999.61, 952.29 and $844.18 \mathrm{~N} / \mathrm{mm}^{2}$, while towards from the matured, intermediate and young maturity group for bottom portion were 999.61, 979.15 and 935.36 $\mathrm{N} / \mathrm{mm}^{2}$ respectively.

The result for MOR in static bending obtained using phenol formaldehyde resin of the matured maturity group from the bottom, middle and top portions were 16.66, 12.55 and $11.72 \mathrm{~N} / \mathrm{mm}^{2}$ respectively, while $16.66,14.38$ and 12.16 $\mathrm{N} / \mathrm{mm}^{2}$ were the data observed from the matured, intermediate and young maturity groups for the bottom portion. This decrement trend happened too in determination MOR for urea formaldehyde bio-composite lumbers towards maturity groups and portions. The MOR values decreased for the oil palm fronds bio-composite lumbers from the bottom, middle and top portions for each maturity group including towards the matured, intermediate and young maturity groups for every portions.

The MOR in compression strength of the oil palm fronds bio-composite lumbers decreases along the bottom to top portions for each maturity group including through the matured to young maturity groups for every portion both of phenol and urea formaldehyde bio-composite lumbers like the data arrangement of 473.17, 395.93 and $260.22 \mathrm{~N} / \mathrm{mm}^{2}$ for the matured maturity group towards the bottom, middle and top portion of phenol formaldehyde bio-composite lumbers.

The maturity groups of the oil palm fronds influences the decrement value of MOR in compression strength can be seen as a comparison on the bottom portion from the matured, intermediate and young maturity groups of phenol formaldehyde bio-composite lumbers which were 473.17, 453.67 and $301.46 \mathrm{~N} / \mathrm{mm}^{2}$ respectively.

\section{REFERENCES}

[1] Uysal, B. 2005. Bonding strength and dimensional stability of laminated veneer lumbers manufactured by using different adhesives. Journal of Adhesion and Adhesives. 25: 395-403.

[2] Zulkifli, R., Mohd Nor, M. J., Mat Tahir, M. F. Ismail, A. R. and Nuawi, M. Z. 2008. Acoustic properties of multi-layer coir fibres sound absortion panel. Journal of Applied Sciences. 8 (20): 37093714.

[3] Hill, C. A. S., Abdul Khalil, H. P. S. and Hale, M. D. 1998. A study of the potential of acetylation to improve the properties of plan fiber. Journal of Industrial Crops and Products. 8: 53.

[4] Mohamad, H., Anis, M. and Wan Hasamudin, W. H. 2003. Energizing the wood-based industry in Malaysia. Proceedings of the $6^{\text {th }}$ National Seminar on The Utilisation of Oil Palm Tree, December 15-17, 2003, Oil Palm Tree Utilisation Committee (OPTUC), Kuala Lumpur, Malaysia. 6-13.

[5] Wahid, M. B., Abdullah, S. N. A. and Henson, I. E. 2004. Oil palm Achievements and potential in new directions for a diverse planet. Proceedings of the $4^{\text {th }}$ International Crop Science Congress, September 26 - October 1, 2004. Brisbane, Australia.

[6] Astimar, A. A., Mohamad, H. and Anis, M. 2002. Preparation of cellulose from oil palm empty fruit bunches via ethanol digestion: Effect of acid and alkali catalysts. Journal of Oil Palm Research. 14 (1): 9-14.

[7] Tanaka, R., Peng, L. C. and Wan Rosli, W. D. 2002. Preparation of cellulose pulp from oil palm empty fruit bunches (EFB) by processes including pre-hydrolysis and ozone bleaching. Proceedings of the USM-JIRCAS Joint International Symposium-Lignocellulose-
Material of the Millenium: Technology and Application, March 2021, 2001, Penang, Malaysia. 33-8.

[8] Ridzuan, R., Stephen, S. and Mohd Ariff J. 2002. Properties of medium density fibreboard from oil palm empty fruit bunch fibre. Journal of Oil Palm Research. 14 (2): 34-40.

[9] Mohamad, H., Ridzuan, R., Anis, M., Wan Hasamudin, W. H., Kamaruddin, H., Ropandi, M. and Astimar, A. A. 2002. Research and development of oil palm biomass utilization in wood-based industries. Journal of Palm Oil Developments. 36: 1-5.

[10] Laemsak, N. and Okuma, M. 2000. Development of boards made from oil palm frond II: Properties of binderless boards from steamexploded fibres of oil palm. Journal of Wood Science. 46 (4): 322326.

[11] Chew, T. L. 1987. Particleboard manufactured from oil pal stems: A pilot scale study. FRIM Occasional Paper No. 4. Kepong: Forest Research Institute Malaysia (FRIM). 8.

[12] Kochummen, A. M., Wong, W. C. and Killmann, W. 1990 Manufacture of cement board using oil palm stems. Unpublished IDRC Final Report.

[13] Abraham, J. M., Zakaria, M. A., Mohd Nor, M. Y. and Simatupang, M. H. 1998. Suitability of kraft pulp from oil palm trunk for cellulose fibre reinforced cement boards. Journal of Tropical Forest Product. 4 (2): $65-159$.

[14] Schwarz, H. G. 1985. Cement-bonded boards in Malaysia. Proceedings of the fibre and particleboards bonded with inorganic binders, Forest Research Soc, USA. 91-93.

[15] Liew, K. C., Jalaluddin, H., Paridah, M. T., Khairul Zaman, M. D. and Mohd Nor, M. Y. 2000. Properties of oil palm frondpolypropylene composite. Proceedings of the Utilization of Oil Palm Tree-Oil Palm Biomass: Opportunities and Challenges in Commercial Exploitation. 8-116.

[16] Ho, K. S., Choo, K. T. and Hong, L. T. 1985. Processing, seasoning and protection of oil palm lumber. Proceedings of the National Symposium on Oil Palm by-products for Agrobased Industries, November 5-6, 1985, Kuala Lumpur, Malaysia. 43-51.

[17] Othman, S., Rokiah, H., Razak, W., Hashim, W. S. and Azmy, M. 2008. Evaluation on somefinishing properties of oil palm plywood. Journal of Holz Roh Werkst. 66: 5-10.

[18] Razak, W., Hashim, W. S., Aminuddin, M., Othman, S. and Rafidah, S. 2008. Properties of laminated veneer lumbers from oil palm trunks. Journal of Plant Sciences. 3 (4): 255-259.

[19] International Organization for Standardization 3131-1975. Switzerland: Wood Determination of Density for Physical and Mechanical Tests.

[20] International Organization for Standardization 3349-1975. Switzerland: Wood Determination of Modulus of Elasticity in Static Bending.

[21] International Organization for Standardization 3133-1975 Switzerland: Wood Determination of Ultimate Strength in Static Bending.

[22] International Organization for Standardization 3787-1976. Switzerland: Wood Determination of Ultimate Compression Stress Parallel to Grain.

[23] Abdullah, C. K. 2010. Impregnation of Oil Palm Trunk Lumber (OPTL) using Thermoset Resins for Structural Applications. Master Thesis. Universiti Sains Malaysia.

[24] Mohamad, H., Zin, Z. Z. and Abdul Halim, H. 1985. Potentials of oil palm by products as raw materials for agro-based industries. Proceedings of National Symposium on Oil Palm by-product for Agro-based Industries, Kuala Lumpur, Malaysia.

[25] Rowell, R. M. 1994. Chemical of Solid Wood. Subtitled by Suhaimi Muhammed and Halimathon $\mathrm{Hj}$ Mansor. Kuala Lumpur: Dewan Bahasa dan Pustaka.

[26] Haygreen, J. G. and Bowyer, J. L. 1930. Introduction to Forest Product and Wood Science. Subtitled by Suhaimi Muhammed and Sheikh Abdul Karim Yamani Zakaria. Kuala Lumpur: Ampang Press Sdn. Bhd.

[27] Paridah, M. T. and Anis, M. 2008. Process optimization in the manufacturing of plywood from oil palm trunk. Proceedings of $7^{\text {th }}$ National Seminar on the Utilization of Oil Palm Tree, Oil Palm Tree Utilization Committee, Kuala Lumpur, Malaysia. 12-24.

[28] Erwinsyah. 2008. Improvement of Oil Palm Wood Properties Using Bioresin. PhD Thesis. Technische Universität Dresden.

[29] Tsoumis, G. 1991. Science and Technology of Wood - Structure, Properties and Utilization. New York: Van Nostrand Reinhold. 
[30] Bowyer, J. L., Shmulsky, R. and Haygreen, J. G. 2004. Forest Product and Wood Sciences - An Introduction (4 ${ }^{\text {th }}$ Edition). Blackwell Publishing Company.

[31] Walker, J. C. F., Butterfield, B. G., Langrish, T. A. G., Harris, J. M and Uprichard, J. M. 1993. Primary Wood Processing ( $1^{\text {st }}$ Edition). London: Chapman and Hall.

[32] Rulliarty, S. and America, W. A.1995. Natural Variation in Wood Quality Indicators of Indonesian Big Leaf Mahogany(Swietenia macrophylla. King). Proceedings of XX IUFRO World Congress, Tampere.

[33] Desch, H. E. 1968. Timber, Its Structure, properties and utilization. New York: London and Basingstoke Associated companies.

[34] Thanate, R., Tanong, C. and Sittipon, K. 2006. An investigation on the mechanical properties of trunks of palm oil trees for the furniture industry. Journal of Oil Palm Research. 114-121.
[35] Ronald, W. W. and Gjinoli, A. 1997. The Use of Recycled Wood and Paper in Building Applications. Proceedings of Forest Product Society No. 7286. 84-91.

[36] John, R. L. and Reid, R. J. 1969. Compressive Strength of Boron Composites. Journal of Composite Materials. 3: 48-8.

[37] Oyagade, A. O. and Fasulu, S.A. 2005. Physical and Mechanical Properties of Trilepisium madagascariense and Funtumia elastica Wood. Journal of Tropical Forest Science.17(2): 258-264.

[38] Nordahlia, A. S. 2008. Wood Quality of 10-Year-Old Sentang (Azadirachta excelsa) Grown from Seedlings and Rooted Cuttings. Master Thesis. University Putra Malaysia.

[39] Baldwin, R. F. 1995. Adhesives and Bonding Techniques. In: Plywood and Veneer-based Products Manufacturing Practuces. California: Miller Freeman Inc. 